\title{
Uji Validitas, Struktur Internal, dan Measurement Invariance pada Alat Ukur Achievement Goal Orientation
}

\author{
Jamaludin \\ UIN Syarif Hidayatullah Jakarta, Indonesia \\ Jamaludin@gmail.com
}

\begin{abstract}
Achievement goal orientation ( $A G O)$ is the goal orientation to achieve achievement. This study aims to explore information about the achievement goal orientation ( $A G O$ ) measurement tool. This study combines two AGO measurements (original and revised) developed by Midgley et al (1998, 2000) based on the Manual for the patterns of adaptive learning scales (PALS). In this study only measured two of the three dimensions analyzed, namely $A G O$ performance and $A G O$ mastery. The sample in this study amounted to 544 people from three junior high schools in West Jakarta. Twenty-one items (IO items AGO performance and II items AGO mastery) were tested for validity, internal structure, and invariance measurement. The results of the validity of the CFA found that AGO performance and $A G O$ mastery were not appropriate to measure the dimensions of $A G O$. Based on the results of internal structure analysis, the bifactor model is more valid and appropriate in measuring AGO performance and AGO mastery. The results of the Bifactor AGO performance analysis are divided into factors of "doing your best" and "looking smart" while AGO mastery is divided into "liking the task" and "understanding the task". There are only five AGO performance items and seven unidimensional $A G O$ mastery items. In the inter-gender validity test, it was found that men are oriented towards $A G O$ performance while women are oriented towards AGO mastery. MGCFA analysis results that $A G O$ performance is valid up to the metric invariance stage while $A G O$ mastery is not invariance.
\end{abstract}

Keywords: Achievement goal orientation (AGO); PALS, validity; internal structure; bifactors; measurement invariance; $M G C F A$

\begin{abstract}
Abstrak
Achievement goal orientation (AGO) adalah orientasi tujuan untuk mencapai prestasi. Penelitian ini bertujuan untuk mengeksplorasi informasi mengenai alat ukur achievement goal orientation (AGO). Penelitian ini menggabungkan dua pengukuran AGO (original dan direvisi) yang dikembangkan oleh Midgley et al (1998, 2000) berdasarkan Manual for the patterns of adaptive learning scales (PALS). Pada penelitian ini hanya mengukur dua dari tiga dimensi yang dianalisis yaitu AGO performance dan AGO mastery. Sampel pada penelitian ini berjumlah 544 orang dari tiga sekolah menengah pertama di Jakarta Barat. Keduapuluh satu item (IO item AGO performance dan II item AGO mastery) diuji validitas, struktur internal, dan measurement invariance. Hasil validitas CFA ditemukan bahwa AGO performance dan AGO mastery tidak sesuai mengukur dimensi AGO. Berdasarkan hasil analisis struktur internal, model bifaktor lebih valid dan sesuai dalam mengukur AGO performance dan AGO mastery. Hasil analisis bifaktor AGO performance terbagi menjadi faktor "melakukan yang terbaik" dan "terlihat pintar" sedangkan AGO mastery terbagi menjadi "menyukai tugas" dan "memahami tugas". Hanya terdapat lima item AGO performance dan tujuh item AGO mastery yang bersifat unidimensional. Pada uji validitas antar gender, dihasilkan bahwa laki-laki berorientasi pada AGO performance sedangkan perempuan berorientasi pada AGO mastery. Analisis MGCFA dihasilkan bahwa AGO performance valid sampai tahap metric invariance sedangkan AGO mastery tidak invariance.
\end{abstract}

Kata kunci: Achievement goal orientation (AGO); PALS; validity; internal structure; bifactors; measurement invariance; MGCFA 


\section{Pendahuluan}

Rendahnya mutu pendidikan Indonesia menjadi masalah dalam meningkatkan pencapaian tujuan ke standar nasional maupun inter-nasional. Hal tersebut terjadi karena masih terdapat kesenjangan mutu pendidikan yang menyebabkan rendahnya tujuan individu. Sementara itu, tujuan merupakan kunci dalam mencapai prestasi (Santrock, 20II). Dibutuh-kan sebuah kompetensi agar individu menghasilkan prestasi yang tinggi dan terbaik dibandingkan orang lain (Darnon, Dompnier, \& Poortvliet, 20I2). Kompetensi tersebut berguna sebagai standar yang digunakan untuk performa evaluasi individu (Ames, I988; Elliot \& Dweck, I988; Elliot \& McGregor, 200I).

Hasil survei lembaga pemeringkatan dunia The Learning Curve Pearson (20I4), Indonesia menempati posisi terakhir dari 40 negara atau dalam posisi degredasi. Posisi Indonesia merupakan yang terburuk dari lima negara dengan ranking terbawah, yaitu Meksiko, Brasil, Argentina, Kolombia, dan Thailand yang berada di atas Indonesia. Di dalam kategori kemampuan kognitif, Indonesia mendapatkan nilai -I,7I; pada nilai pencapaian pendidikan, Indonesia mendapatkan nilai -2,I I; dan pada indeks global, Indonesia mendapatkan nilai -I,84.

Hasil yang sama ditunjukkan pada studi internasional Trend in International Mathematics and Science Study (TIMSS, 20I5), bahwa Indonesia berada pada posisi degredasi dengan 397 poin. Indonesia menempati posisi ke-45 dari 50 negara pada mata pelajaran Matematika dan posisi ke-45 dari 48 negara pada mata pelajaran Sains. Hasil studi tersebut disimpulkan bahwa mutu pendidikan di Indonesia berada di bawah negara timur tengah seperti Oman (425 poin), Iran (43I poin), Qatar (439 poin), dan Bahrain (45I poin), dengan peringkat pertama ditempati oleh Singapura (618 poin).

. Hasil ujian nasional (UN) 2016 menunjukkan bahwa nilai integritas pelajar SMP dan SMA meningkat, tetapi standar nilai kelulusan menurun. Standar penurunan rata-rata nilai UN terjadi di semua pelajaran SMP antara 2015 dan 20I6, yaitu Matematika -6,04 poin, Ilmu Pengetahuan Alam (IPA) -3,6I poin, Bahasa Inggris $-2,84$ poin, dan Bahasa Indonesia $-0,3 \mathrm{I}$ poin. Nilai rata-rata UN pada tahun 20I6, SMP adalah sebesar 58,57, MTs 59,06, dan SMP Terbuka 48,36. Kemudian, rata-rata nilai UN 2016 untuk jenjang SMA dan sederajat mengalami penurunan dibandingkan tahun 20I5. Rata-rata nilai UN SMA 2015 dan 2016 adalah 6I,93 dan 55,3 atau mengalami penurunan 6,9 poin.

Di 2016, sistem UN diubah Kementrian pendidikan dan budaya (Kemendikbud, 2016) menjadi sistem berbasis integritas untuk meningkatkan mutu pendidikan di Indonesia. Sistem tersebut merupakan sistem yang berlandaskan pada nilai-nilai kejujuran untuk melihat potensi dan kemampuan siswa yang sebenarnya. Penentuan kelulusan pada siswa tersebut tidak didasarkan oleh nilai UN, tetapi ditentukan oleh sekolah melalui rapat dewan guru.

Fakta-fakta tersebutmembuktikan bahwa kualitas pendidikan secara nasional dan internasional masih sangat rendah. Salah satu penyebab rendahnya kualitas pendidikan ialah karena kurangnya orientasi tujuan siswa untuk mencapai prestasi atau disebut dengan achievement goal orientation (Santrok, 20I I).Achievement goal orientation (AGO) di ranah akademis berhubungan dengan kemampuan individu pada pencapaian tugas dan perilaku untuk mencapai sebuah prestasi (VandenBos 2005). Individu yang memiliki AGO tinggi cenderung mengarahkan pencapaian tujuan jangka panjang (Santrock, 20II; VandenBos, 20I5) pada perilaku, afeksi, kognisi (Elliot, I999), dan pengalamannya (Dweck \& Legget, I988).

Achievement goal orientation (AGO) pada dasarnya dibagi menjadi dua, yaitu performance dan mastery. Individu yang berorientasi mastery berfokus pada penguasaan materi, pengembangkan pengetahuan, dan pemahaman kompetensi. Belajar dianggap sesuatu yang menarik dan menyenangkan dalam menyelesaikan tugas (Ames, 1992; Ames \& Archer, 1988; Archer, I994; Fisher \& Ford, I998; Midgley et.al., I998; 2000). 
Individu yang berorientasi pada mastery lebih kompetitif dalam belajar (Midgley, Kaplan, \& Middleton, 200I) dan berusaha untuk menguasai segala tugas yang diberikan oleh guru (Elliot \& Thrash, 200I).

Individu yang berorientasi pada performance berfokus untuk menunjukkan kemampuan yang terbaik dibandingkan orang lain. Belajar dianggap sesuatu hal untuk mencari nilai yang tertinggi (Midgley et.al., I998; 2000; Elliot \& McGregor, 200I). Individu yang berorientasi pada mastery lebih kompetitif dalam belajar, sedangkan individu yang berorientasi pada performance lebih cenderung melakukan strategi untuk menghindari nilai yang buruk, menyontek, dan kurang ingin bekerja sama dengan temannya (Midgley et.al., 200I). Ciri-ciri tersebut membuktikan, bahwa pelajar di Indonesia berorientasi pada performance dibandingkan mastery. Hal ini karena masih terdapat kecurangan dalam ujian nasional (misalnya: mencontek atau berbuat) setiap tahunnya (Wurinanda, 2016 dalam news.okezone.com).

Berdasarkan hasil studi eksperimen yang dilakukan Curry et.al. (2002), achievement goal dipengaruhi oleh motivasi intrinsik pada remaja awal dalam tugas-tugas motorik di sekolah. Penelitian Liu, Wang, Tan, Ee, dan Koh (2009) menunjukkan bahwa achievement goal dipengaruhi oleh motivasi intrinsik (kesenangan, usaha, nilai) dan persepsi hasil pada kemampuan individu (komunikasi, kolaborasi, dan pemecahan masalah). Dimensi mastery diasosiasikan oleh pola negatif pada perubahan dalam self-regulation, self-efficacy, pengaruh positif atau negatif di sekolah, peringkat, dan transisi kenaikan kelas (Urdan \& Midgley, 2003), serta mempengaruhi tujuan pada masa transisi dari SMP menuju SMA, SMK, dan Universitas (Meier et.al,. 20I3).

\section{Perbedaan jenis kelamin pada AGO Perempuan lebih cenderung pada}

Orientasi mastery dan laki-laki lebih cenderung pada orientasi performance (Pajares \& Cheong, 2003; Theis $\&$ Fischer, 2017). Pria cenderung berfokus pada orientasi performance dalam mencapai prestasi (Urdan, 1997). Individu yang berorientasi performance lebih cenderung ingin mencari popularitas dan keuntungan (Lee, McInerney, Liem, \& Ortiga, 2010). Perempuan lebih berfokus untuk mengembangkan dan meningkatkan kompetensinya dibandingkan laki-laki yang lebih santai dalam berkompetisi (Pajares \& Cheong, 2003). Fakta sebaliknya ditemukan pada penelitian Fryer dan Elliot (2007), yang menunjukkan bahwa tidak ada perbedaan jenis kelamin dalam mencapai sebuah prestasi dan tidak ada perbedaan yang signifikan pada jenis kelamin laki-laki dan perempuan pada dimensi performance (Steinmayr \& Spinath, 2008).

\section{Validitas AGO}

Selain menggunakan observasi atau tes, untuk mengetahui orientasi tujuan berprestasi siswa AGO performance atau AGO mastery, dapat dilakukan dengan alat ukur psikologi (Duda \& Nicholls, I992). Alat ukur AGO yang diteliti oleh Midgley et.al. (1998, 2000) yang dikembangan dari patterns of adaptive learning scale (PALS) menjadi fokus pada penelitian ini. Alat ukur tersebut telah diadaptasi dan divalidasi ke berbagai bahasa atau negara, misalnya Jepang, Kanada (Murayama, Zhou, Nesbit, 2008), Taiwan (Shih, 2005; 2008), Yunani (Gonida et.al., 2007; 2009), China (Salili \& Lai, 2003), dan Meksiko (Rinthapol \& Durán, 20II). Namun, untuk diadaptasi ke bahasa Indonesia belum ada peneliti yang mengembangkannya.

Sebuah alat tes dikatakan valid jika mampu mengukur apa yang hendak diukur (Allen \& Yen, 1979). Pada penelitian Midgley et.al. (2000), skala AGO valid pada sampel SD dan SMP di negara bagian Midwestern Amerika. Uji validitas dan Exploration factor analysis (EFA) yang dilakukan oleh Rinthapol dan Durán (20II) dihasilkan item-item yang valid mengukur dua dimensi, yaitu mastery dan performance pada siswa SMP dan SMA di Meksiko. Hal yang sama pada penelitian Muis, Winne, dan Edwards (2009), indikator pada alat ukur AGO valid dan reliabel mengukur mahasiswa Universitas Amerika Serikat dan Cina (Chen, 20I5). Alat ukur AGO valid mengukur sampel SMA (Hackel, Jones, Carbonneau, \& Mueller, 20I6) dan sesuai dengan sampel SMA di pedesaan dan perkotaan Afrika Amerika (Hart, Mueller, Royal, \& Jones, 20I3). 


\section{Multi-group pada AGO}

Salah satu cara untuk meningkatkan kualitas alat ukur AGO di ranah pendidikan adalah dengan metode measurement invariance. Metode tersebut digunakan untuk menghindari dari bias gender pada alat ukur (Brown, 2006; Byrne, 2012). Salah satu metode multigroup confirmatory factor analysis (MGCFA) yang digunakan dalam memban-dingkan dua kelompok atau lebih. Penelitian Murayama, Zhou, dan Nesbit (2008) menggunakan sampel lintas budaya pada

Universitas Jepang dan Kanada. Metode multigroup confirmatory factor analysis (MGCFA) digunakan dalam membandingkan gender. Hasilnya, metric invariance mengindikasi pada empat faktor struktur. Campbell, Barry, Joe, dan Finney (2008) memodifikasi skala AGO dan menarik kesimpulan bahwa, fungsi AGO sama lintas kelompok serta valid pada sampel mahasiswa Afrika, Amerika dan kulit putih. Schwinger, Steinmayr, dan Spinath (2016) menggunakan model yang secara signifikan sampai ke tahap strong invariance pada dimensi performance dan mastery. Midgley et.al. (1998) pada hasil penelitiannya, hanya sampai pada model metric invariance.

Pengujian measurement invariance (MI) dimaksudkan untuk mencari apakah konstruk AGO sama pada kelompok tertentu, misalnya mengandung bias gender atau memiliki latar belakang budaya yang berbeda. Berdasarkan fenomena-fenomena yang peneliti paparkan, penelitian ini dianggap perlu karena bermanfaat untuk meningkatkan mutu pendidikan bagi individu dan lembaga pendidikan di Indonesia. Manfaat lain ialah sebagai standar kompetensi agar peserta didik dapat mencapai tujuan ke tingkat pendidikan yang lebih tinggi.

\section{Perkembangan AGO}

Achievement goal orientation (AGO) berkembang dengan berbagai istilah dalam dimensinya, seperti performance goal dan learning goal (Dweck, 1986; Dweck \& Leggett, 1988; Elliot \& Dweck, I988), tugas dan ego (Duda \& Nicholls, 1992; Nicholls 1984; Nicholls, Cheung, Lauer, \& Patashnick, I989; VandenBos, 2015), performance dan mastery (Ames, 1992; Ames \& Archer, 1988; Archer, I994; Fisher \& Ford, 1998).

AGO menurut Midgley et.al. (1998; 2000) memiliki tiga dimensi orientasi, yaitu task atau mastery, performance-approach, dan performance-avoidance. Orientasi tujuan task mengarah pada pengembangan kemampuan individu; performance-approach mengarah pada orientasi tujuan untuk mendemonstrasikan kemampuan kepada orang lain; dan performance-avoidance merupakan orientasi tujuan untuk menghindari ketidakmampuan dalam mendemonstrasikan segala kemampuan-nya.

Elliot dan koleganya (Elliot, 1997, 1999; Elliot \& Church, 1997; Elliot \& McGregor, 200I; Elliot \& Murayama, 2008; Elliot, Murayama, \& Pekrun, 20II) membuat alat ukur achievement goal questionnaire (AGQ). Pada alat ukur AGQ terdapat 4 dimensi yaitu: mastery-approach (MAP), mastery-avoidance (PAV), perfor-mance-approach (PAP), dan performance-avoidance (MAV).

MAP mempresentasi-kan usaha untuk mencapai penguasaan suatu tugas; PAV mempresentasikan individu berusaha agar tidak gagal dalam menguasai suatu tugas atau usaha individu agar tidak kehilangan kemampuan, ke-terampilan dan pengetahuan; PAP mem-presentasikan usaha individu untuk lebih baik dari orang lain; dan MAV mem-presentasikan individu berusaha dalam menghindari atau tidak melakukan hal yang buruk dibandingkan orang lain.

Peneliti berkesimpulan bahwa AGO didasarkan atas dua orientasi, yaitu AGO performance dan AGO mastery. Hal tersebut karena AGO merupakan karakter kepribadian individu dalam belajar. Akhirnya, apabila individu berlandasakan pada approach atau avoidance, itu sama saja seperti item di-reverse (dibalik) atau dari item favourable menjadi unfavourable. Hal terjadi ketika dua pengukuran diujikan pada seseorang, maka terdapat empat kelompok yaitu rendah AGO performance - rendah AGO mastery (-P $-\mathrm{M})$, tinggi AGO performance - rendah AGO mastery $(+\mathrm{P}-\mathrm{M})$, rendah AGO performance - tinggi AGO mastery $(-\mathrm{P}+\mathrm{M})$, 
tinggi AGO performance - tinggi AGO mastery (+P +M). Di dalam penelitian Pintrich (2000a, 2000b), peran orientasi tujuan dalam belajar dan berprestasi merupakan multiple goals yang menjelaskan tentang perbedaan kelompok dan multiple pathways yang berarti bagaimana cara individu dapat mencapai prestasi di sekolah.

\section{Metode}

\section{Sampel}

Sampel penelitian di SMP Negeri 108 Jakarta dan SMP Negeri 249 Jakarta adalah siswa-siswi kelas 7 dan 8 tahun ajaran 2016/2017 dan 2017/2018, SMP Yayasan Pendidikan dan Pengembangan Islam AsSaudiyah (YAPIS), yaitu siswa yang bersekolah pada tahun ajaran 2015/2016 sampai 2017/2018. Jumlah partisipan dalam penelitian ini terdiri dari tiga populasi Sekolah Menegah Pertama (SMP), yaitu SMP Yayasan Pendidikan dan Pengembangan Islam As-Saudiyah (YAPIS) berjumlah 80 pertisipan (I4.7\%), SMP Negeri 108 Jakarta berjumlah 200 partisipan (36.8\%), dan SMP Negeri 249 Jakarta berjumlah 264 partisipan (48.5\%). Total sebanyak 545 partisipan yang mengisi alat ukur AGO. Namun, terdapat I partisipan yang tidak mengisi lembar penyataan secara penuh, maka total partisipan pada penelitian ini berjumlah 544 orang dengan 307 (56.4\%) perempuan.

\section{Instrumen}

Alat pengumpul data dalam penelitian ini menggunakan instrumen penelitian Midgley et.al. (I998; 2000). Instrumen alat ukur AGO merupakan gabungan dari AGO original tahun 1998 dan AGO yang direvisi tahun 2000. Terdapat 2 dimensi yang diteliti dalam alat ukur AGO, yaitu perfrormance dan mastery yang masingmasing dimensinya terdapat IO item dan II item.

Seluruh item AGO diukur melalui empat kategori skala likert, yaitu dari sangat setuju (4) sampai dengan sangat tidak setuju (I). Hal tersebut dilakukan untuk menghindari pilihan yang terpusat (central tendency) atau menghindari respon yang bersifat netral.

Prosedur adaptasi skala yang peneliti lakukan bersumber pada penelitian Brislin (I970). Terdapat tujuh tahapan dalam pengadaptasian skala, yaitu penyamaan struktur, komite, back-translation, me-rating, pretes, evaluasi, dan reporting.

\section{Aplikasi}

Aplikasi yang digunakan adalah program Mplus7 (Muthen \& Muthen, 20I2). Program ini memiliki logika penulisan sintaks analisis yang lebih mudah jika dibandingkan dengan LISREL Matrix Programming yang cenderung rumit.

\section{Hasil dan Pembahasan}

\section{Validitas}

Berdasarkan hasil analisis CFA yang dilakukan dengan model satu faktor, ternyata tidak fit mengukur AGO performance dan AGO mastery. Hasil CFA AGO performance $\chi^{2}(35)=488.630(p<0.00 \mathrm{I}$, RMSEA $=$ 0.154 (90\% C.I $=0.142$, 0.I67), CFI $=0.85 \mathrm{I}$, dan TLI $=0.808$. Hasil analisis CFA AGO mastery dengan $\chi^{2}(44)=367.538, P_{\text {-value }}<0.00 \mathrm{I}, \mathrm{RMSEA}=0 . \mathrm{II} 6$, dan nilai $\mathrm{CFI}=0.866$ 
Tabel I memperlihatkan item-item yang valid namun hasil membuktikan bahwa AGO performance dan AGO Matery tidak sesuai dengan yang diteorikan dan dengan data penelitian maka hipotesis nihil tidak diterima. Artinya, teori tidak sesuai dengan data dikarenakan nilai RMSEA $>0.05$ dan nilai chi-square signifikan $p$-value $<0.05$, maka dapat dinyatakan bahwa model dengan satu faktor tidak dapat diterima.

\section{Struktur Internal}

Seluruh item AGO performance fit mengukur apa yang hendak diukur jika residual atau kesalahan item (theta delta) saling dibebaskan (free). Kesalahan item terjadi dikarenakan mengukur hal lain. AGO performance diketahui terdapat sembilan item yang saling berkorelasi, yaitu AGO3 dengan AGOI dan AGO2, AGO7 dengan AGO6 dan AGO8, AGO8 dengan AGO6, AGO9, AGOI0, dan AGO9 dengan AGO4 dan AGOI0. Hasil model fit pada modifikasi model AGO performance diperoleh $\chi^{2}(26)=81.616$ $(P<0.00 \mathrm{I}), \mathrm{RMSEA}=0.062,90 \%$ C.I $=0.047$ 0.078, CFI $=0.962$, dan TLI $=0.969$.

Tabel I. Koefisien AGO Performance dan AGO Mastery

\begin{tabular}{|c|c|c|c|c|c|c|c|}
\hline \multirow[b]{2}{*}{ Item } & \multicolumn{3}{|c|}{ AGO performance } & \multirow[b]{2}{*}{ Item } & \multicolumn{2}{|c|}{ AGO mastery } & \multirow[b]{2}{*}{ Est./S.E. } \\
\hline & Estimate & S. E & Est./S.E. & & Estimate & S.E & \\
\hline AGOI & .433 & .039 & II.I47 & AGOII & $.37 \mathrm{I}$ & .04I & 9.109 \\
\hline AGO2 & .573 & .033 & I7.273 & AGOI2 & .567 & .033 & I7.086 \\
\hline AGO3 & .603 & .033 & $\mathrm{I} 8.44 \mathrm{I}$ & AGOI3 & .546 & .035 & I5.788 \\
\hline AGO4 & .666 & .026 & 25.633 & AGOI4 & .582 & .033 & $\mathrm{I} 7.873$ \\
\hline AGO5 & .650 & .028 & 22.872 & AGOI5 & .445 & .038 & I I. 853 \\
\hline AGO6 & .549 & .033 & I6.837 & AGOI6 & .422 & .040 & 10.666 \\
\hline AGO7 & .542 & $.03 \mathrm{I}$ & I7.397 & AGOI7 & .672 & .033 & 20.422 \\
\hline AGO8 & $.66 \mathrm{I}$ & .029 & 22.885 & AGOI8 & .657 & .030 & 22.182 \\
\hline AGO9 & .778 & .022 & 35.162 & AGOI9 & .688 & .025 & 27.857 \\
\hline \multirow[t]{2}{*}{ AGOIO } & .736 & .023 & 32.643 & AGO20 & .666 & .026 & 25.538 \\
\hline & & & & AGO2I & 649 & .032 & 20.285 \\
\hline
\end{tabular}

Keterangan. S.E $=$ Standard Error; Est./S.E = Estimate/ S.E; $N=544$.

Tabel 2. Struktur Internal AGO

\begin{tabular}{lll}
\hline Item & $\begin{array}{l}\text { Pernyataan } \\
\text { AGO Performance }\end{array}$ & $\lambda^{a}$ \\
AGOI & $\begin{array}{l}\text { Saya akan benar-benar merasa senang jika saya adalah satu-satunya orang yang menjawab } \\
\text { pertanyaan guru di kelas. }\end{array}$ & 460 \\
AGO2 & Saya ingin melakukan yang terbaik dibandingkan siswa lain di kelas. & .567 \\
AGO3 & Saya akan merasa berhasil jika saya melakukan lebih baik daripada kebanyakan siswa lainnya. & 581 \\
AGO4 & Saya ingin menunjukkan kepada guru bahwa saya lebih pintar dari siswa lain di kelas. & .720 \\
AGO5 & Penting bagi saya melakukan yang terbaik dibandingkan siswa lain di kelas. & .755 \\
AGO6 & Penting bagi saya bahwa siswa lain menganggap saya mampu menyelesaikan tugas kelas dengan & .500 \\
& baik. & .528 \\
AGO7 & Salah satu tujuan saya adalah menunjukkan kepada orang lain bahwa saya mampu dalam tugas & .464 \\
& kelas. & .489 \\
AGO8 & Salah satu keinginan saya adalah menunjukkan kepada siswa lain bahwa tugas itu mudah bagi saya. \\
AGO9 & Salah satu tujuan saya adalah untuk terihat pintar dibandingkan dengan siswa lain di kelas. & .537 \\
AGOI0 & Penting bagi saya terlihat pintar dibandingkan dengan orang lain di kelas. & \\
\hline
\end{tabular}

\begin{tabular}{lll}
\hline \multirow{2}{*}{ AGOII } & AGO Mastery & Saya suka tugas apapun di kelas yang akan saya pelajari bahkan jika saya membuat banyak \\
& kasah.
\end{tabular}




\begin{tabular}{lll}
\hline AGOI2 & Alasan penting mengapa saya mengerjakan tugas kelas karena saya suka mempelajari sesuatu yang & .463 \\
baru. & .459 \\
AGOI3 & Saya suka tugas kelas yang bisa membuat saya benar-benar berpikir. & .509 \\
AGOI4 & Alasan utama mengerjakan tugas di kelas karena saya ingin menguasai materi tersebut. & .399 \\
AGOI5 & Alasan penting saya mengerjakan tugas kelas karena saya menikmatinya. & .384 \\
AGOI6 & Saya mengerjakan tugas kelas karena saya tertarik dengan tugas tersebut. \\
AGOI7 & Penting bagi saya untuk belajar banyak materi baru tahun ini. & .704 \\
AGOI8 & Salah satu tujuan saya di kelas adalah belajar sebanyak mungkin yang saya bisa. \\
AGOI9 & Salah satu tujuan saya adalah menguasai banyak keterampilan baru tahun ini. & .697 \\
AGO20 & Penting bagi saya bahwa saya benar-benar memahami tugas kelas. & .729 \\
AGO2I & Penting bagi saya untuk memperbaiki keterampilan saya tahun ini. & .619 \\
\hline
\end{tabular}

Keterangan. ${ }^{2}$ Data merupakan hasil modifikasi kesalahan item; AGO performance = AGOI-AGOIO; AGO mastery $=$ AGOII-AGO2I.

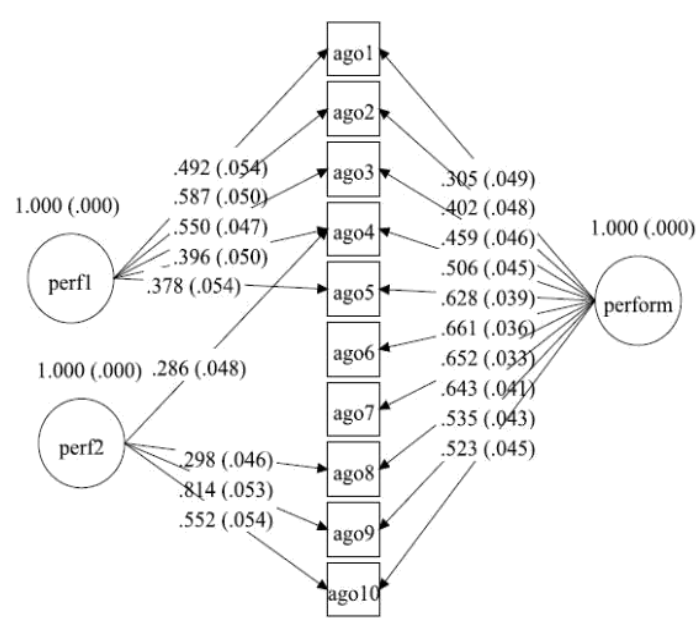

Gambar I. Bifaktor AGO Performance

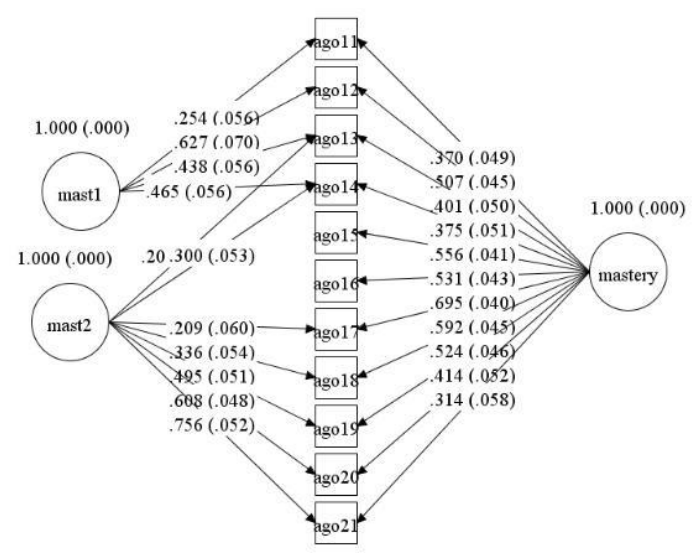

Gambar 2. Bifaktor AGO mastery.

Pada AGO mastery terdapat enam korelasi residual, yaitu AGOI6 dengan AGOI5, AGO2I dengan AGO20, AGOI4 dengan AGOI2 dan AGOI3, dan AGOI3 dengan AGOI2 dan AGOII. Hasil model fit pada modifikasi model AGO mastery diperoleh $\chi^{2}(38)=$ I I2.77I $(P<0.00 \mathrm{I})$, RMSEA $=0.060$ (90\% C.I $=0.048,0.073), \mathrm{CFI}=0.969, \mathrm{TLI}=0.955$. Hasil tersebut valid mengukur AGO mastery. Peneliti menguji apakah ke 10 item mengukur hal lain pada AGO performance. Hasil analisis bifaktor diperoleh $\chi^{2}(26)=$ $73.328(\mathrm{P}<0.00 \mathrm{I})$, RMSEA $=0.058$ (90\% C.I $=0.042$, 0.074), CFI $=0.984$, TLI $=0.973$. Berdasarkan gambar I, item-item perfI, yaitu AGOI-AGO5yangmengukurtentang "melakukan yang terbaik" dan perf2 yaitu AGO4, AGO8-AGOI0 mengukur tentang "terlihat pintar" dimana AGO4 mengukur dua faktor (cross loading). Pada AGO4 selain mengukur tentang "melakukan yang terbaik” namun mengukur hal lain yaitu "terlihat pintar". Berdasarkan gambar 2, hasil analisis pada bifaktor diperoleh $\chi^{2}(33)=105.325(\mathrm{P}<0.00 \mathrm{I})$, 
RMSEA $=0.063(90 \%$ C.I $=0.050,0.077)$, CFI $=0.970$, TLI=0.950. Pada MastI (faktor I) mengukur tentang "menyukai tugas" Sedangkan Mast2 (faktor 2) mengukur tentang "memahami tugas". Berdasarkan tabel 4. diketahui bahwa AGOI3 "Saya suka tugas kelas yang bisa membuat saya benar-benar berpikir" dan AGOI4 "Alasan utama mengerjakan tugas di kelas karena saya ingin menguasai materi tersebut" mengukur dua faktor secara bersamaan. Artinya, kedua item tersebut selain mengukur tentang menyukai tugas tetapi juga mengukur tentang memahami tugas. AGOI5 dan AGOI6, berkoefisien negatif jika arah panah dihubungkan pada kedua faktor tersebut.

\section{Measurement Invariance}

Peneliti menganisis AGO performance dari IO item menjadi empat item yang sesuai dengan konfigurasi struktur model AGO performance. Keempat item AGO performance yang dianalisis, yaitu AGO3, AGO5, AGO7, dan AGOI0. Hasil keempat item tersebut untuk kelompok perempuan didapat dengan nilai indeks fit $\chi_{\text {perempuan }}^{2}(2)=\mathrm{I} .4 \mathrm{I} 8, p>0.05$, dan RMSEA $<0.05$ dengan $90 \% \mathrm{CI}$ antara $0.000-0.102$, CFI $=1.00$, $\mathrm{TLI}=1.00$. Indeks nilai fit $\chi^{2}$ laki-akk $(2)=0.809, p>0.05$, dan RMSEA $<0.05$ dengan indeks pertimbangan $90 \%$ CI antara $0.000-0.099$, CFI $=1.00$, dan TLI $=1.04$.

Tabel 3. Hasil Analisis MI 4 Item AGO Performance

\begin{tabular}{|c|c|c|c|c|c|c|c|c|c|c|}
\hline Model & $\chi^{2}$ & $d f$ & $\begin{array}{l}\text { RMSEA } \\
{[90 \% \mathrm{CI}]}\end{array}$ & CFI & TLI & $\Delta$ Model & $\Delta \chi^{2}$ & $\Delta d f$ & $\Delta \mathrm{CFI}$ & $\Delta \mathrm{TLI}$ \\
\hline Laki-laki & $.809^{*}$ & 2 & $.000[.000,099]$ & 1.00 & I.04 & & & & & \\
\hline Perempuan & $1.418^{*}$ & 2 & $.000[.000, .102]$ & 1.00 & 1.00 & & & & & \\
\hline MI: Configural & $2.162^{*}$ & 4 & $.000[.000, .068]$ & 1.00 & I.OI & & & & & \\
\hline M2: Metric & $7.56 \mathrm{I}^{*}$ & 7 & $.017[.000,078]$ & .999 & .998 & M2-MI & $4.88 \mathrm{I}^{*}$ & 3 & .001 & .002 \\
\hline M3: Scalar & 48.362 & 18 & $.079[.052,106]$ & .933 & .955 & M3-M2 & 39.962 & II & .066 & .043 \\
\hline
\end{tabular}

Berdasarkan tabel 3, Hasil dapat disimpulkan bahwa, AGO performance hanya sampai ke tahap metric invariance. Artinya, secara teori model tersebut yang menyatakan bahwa $\mathrm{H}_{0}$ tidak diterima yang artinya ada perbedaan yang signifikan antara laki-laki dan perempuan. Hasil tersebut berarti teori tidak sesuai (tidak fit) dengan data yang diukur yaitu dengan model perbandingan scalar dengan metric invariance dalam mengukur kelompok laki-laki dan perempuan.

Peneliti menganisis ulang AGO mastery menjadi empat item, yaitu AGOI4, AGOI8, AGO9, dan AGO2I yang sesuai dengan konfigurasi kelompok. Hasil keempat item tersebut untuk kelompok perempuan didapat dengan nilai indeks fit $\chi_{\text {perempun }}^{2}(2)=0.248, p>0.05$, dan RMSEA $<0.05$ dengan indeks pertimbangan 90 $\%$ CI antara $0.000-0.054, \mathrm{CFI}=1.00$, TLI $=$ I.0I. Nilai fit $\chi_{\text {laki-ak }(2)}^{2}=4.690, p>0.05$, dan RMSEA $<$ 0.05 dengan indeks pertimbangan $90 \% \mathrm{CI}$ antara $0.000-0.164$, CFI $=0.986$, dan TLI $=0.957$. Kedua hasil tersebut dapat disimpulkan bahwa model tersebut sesuai dalam mengukur AGO mastery pada perempuan dan laki-laki karena nilai $p>0.05$ dan RMSEA $<0.05$. Tahap awal MI adalah configural, Hasil diperoleh dengan nilai $\chi^{2}\left(4, N=237 ; N_{\text {perempuan }}=307\right)=5.187(p>0.05)$ dan RMSEA $<0.05(90 \% \mathrm{CI}$ antara $0.000-0.102)$, CFI $=0.998$, dan TLI $=0.995$ yang artinya model tersebut fit mengukur model configural invariance pada AGO mastery. Ketika tahap awal MI sesuai dengan data, maka selanjutnya tahap metric invariance, pada tahap metric invariance didapat nilai $\chi^{2}\left(7, N_{\text {laki-laki }}=237 ; N_{\text {perempuan }}=307\right)=21.209$ $(p<0.05)$, RMSEA $>0.05$. Indeks pertimbangan $90 \% \mathrm{CI}$ antara $0.046-0.130$, CFI $=0.980$, dan TLI $=$ 0.965. Hasil model tersebut kurang fit atau sesuai dalam mengukur model metric invariance pada AGO mastery. 
Berdasarkan hasil uji perbandingan model AGO mastery, pada model metric dengan configural invariance didapat $\Delta \chi^{2}\left(3, N=237 ; N_{\text {perempuan }}=307\right)=13.708(p<0.05), \Delta \mathrm{CFI}=0.018$, dan $\Delta \mathrm{TLI}=0.030$. Hasil dapat ditafsirkan bahwa secara teori model tersebut yang menyatakan bahwa Ho tidak diterima yang artinya ada perbedaan yang signifikan antara laki-laki dan perempuan. Hasil tersebut berarti teori tidak sesuai (tidak fit) dengan data yang diukur yaitu dengan model perbandingan metric dengan configural invariance dalam mengukur kelompok laki-laki dan perempuan. Artinya, pada AGO mastery tidak invariance karena $\mathrm{H}_{0}$ tidak diterima atau data tidak sesuai yang diteorikan.

\section{Scoring}

Peneliti selanjutnya membuat tabel konversi skor AGO performance dan AGO mastery agar lebih memudahkan dalam penilaian. Penormaan skor AGO performance dan AGO mastery didasarkan pada nilai cut-off rata-rata true-score individu. Apabila dibawah 50 maka dikategorikan rendah dan apabila diatas 50 maka dikategorikan tinggi. Peneliti menganalisis nilai rata-rata dengan menggunakan raw-score agar sebagai perbandingan dengan nilai true-score.

Tabel 4. Rata-Rata, Standar Deviasi, dan Jumlah Sampel Kelompok AGO

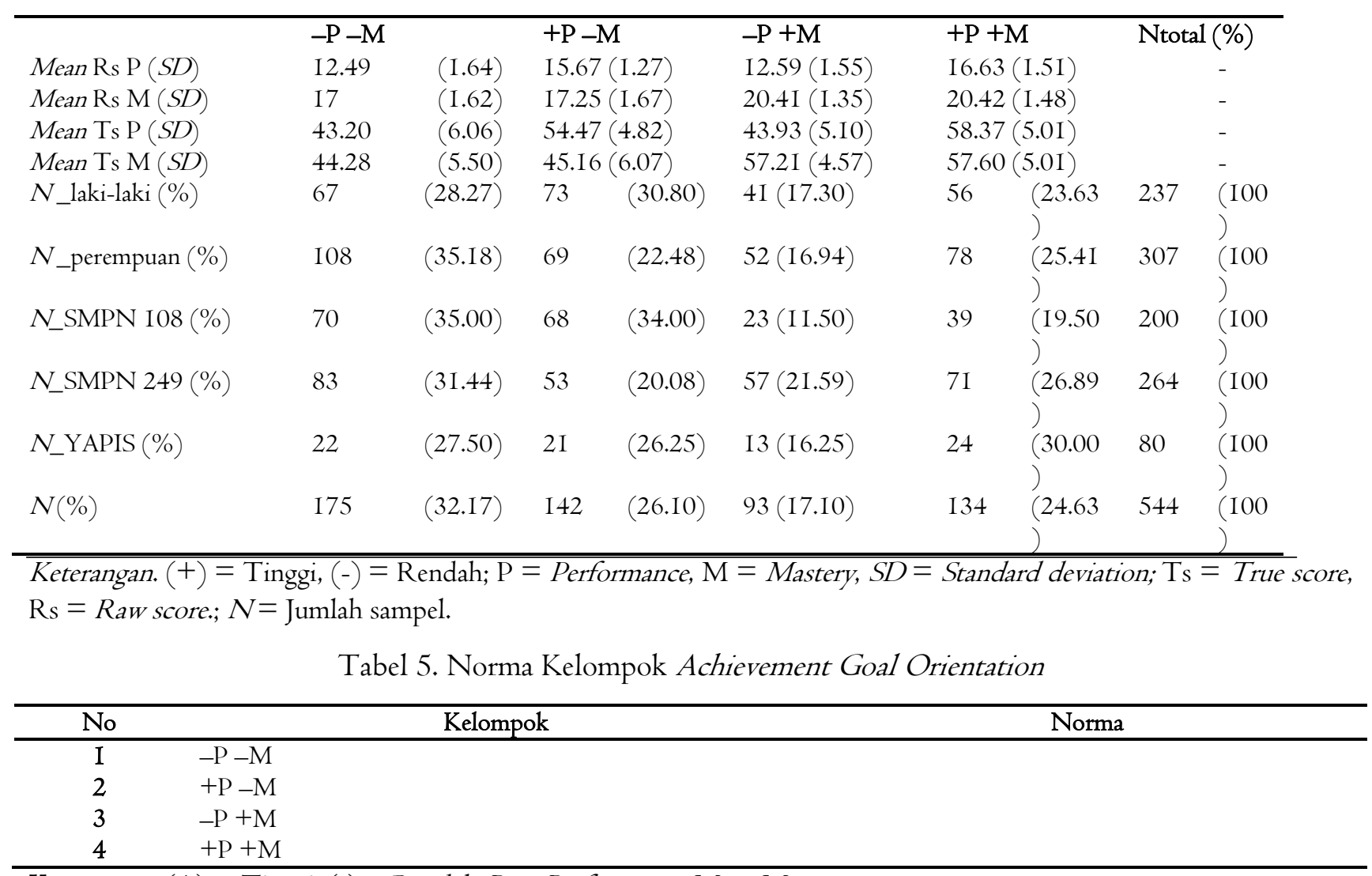

Keterangan. $(+)=$ Tinggi, $(-)=$ Rendah; $\mathrm{P}=$ Performance, $\mathrm{M}=$ Mastery.

Individu kurang menunjukkan kepintarannya kepada guru, kesulitan mengerjakan tugas, kurang terlihat pintar dibandingkan dengan siswa lain di kelas. Individu merasa berhasil jika melakukan lebih baik dibandingkan siswa lainnya, selalu menunjukkan kepintaran dan kemampuanya kepada guru, teman, dan orang lain. Individu menguasai materi yang diajarkan, mempelajari materi yang baru dan sebanyak yang ia bisa, memahami tugas kelas, dan selalu memperbaiki keterampilan dalam belajar. 
Individu melakukan yang terbaik dibandingkan siswa lain, Individu menyukai materi yang membuat ia benar-benar berpikir, menguasai materi yang diajarkan, mempelajari materi yang baru dan sebanyak yang ia bisa, memahami tugas kelas, dan selalu memperbaiki keterampilan dalam belajar.

Berdasarkan tabel 4 diketahui bahwa kelompok -P -M berada posisi yang terbanyak yaitu 175 orang dengan jumlah perempuan terbanyak yaitu 108 (35.18 \%) orang dan bersekolah di SMPN 249 Jakarta sekitar 83 orang (3I.44\%). Kelompok $-\mathrm{P}+\mathrm{M}$ berada diposisi yang terendah yaitu berjumlah 93 orang dengan 4I orang laki-laki (I7.30\%) dan 5I orang perempuan (I6.94\%).

Berdasarkan tabel 5 diketahui bahwa kelompok -P -M memerlukan perhatian khusus dalam mengerjakan tugas dibandingkan kelompok $+\mathrm{P}+\mathrm{M}$ yang sudah mandiri dalam belajar. Di dalam norma kelompok $+\mathrm{P}-\mathrm{M}$ atau kelompok performance, individu menunjukkan kemampuan dan kepintaran (show up) dibandingkan kelompok $-\mathrm{P}+\mathrm{M}$ yang menguasai dan memahami tugas-tugas dalam belajar. Penormaan kelompok AGO agar dapat memudahkan para guru mengobservasi siswa-siswinya dalam meningkatkan prestasi belajar.

\section{Penutup}

Penelitian ini menggabungkan dua instrumen pengukuran AGO (original dan direvisi) yang dikembangkan oleh Midgley, et.al., I998; 2000. Pada penelitian ini hanya mengukur dua dimensi yaitu AGO performance dan AGO mastery yang diadaptasi dari Manual for the patterns of adaptive learning scales (PALS; Midgley, et al. 2000). Penelitian ini juga hanya mengukur skala dari domain secara general yaitu achievement (prestasi) bukan secara spesifik (misalnya, mengukur pelajaran matematika). Kemudian sampel dalam penelitian ini adalah siswa-siswi SMP kelas 7 dan 8 .

Uji validitas AGO performance dan AGO mastery pada penelitian ini sesuai dengan yang diteorikan Midgley, et.al., 1998; 2000. Penelitian ini juga sesuai dengan penelitian lain, seperti Muis, Winne, dan Edwards (2009) yang valid mengukur mahasiswa Universitas Amerika Serikat. Meski demikian, nilai lambda atau estimate AGOII, AGOI5, dan AGOI6 pada AGO mastery tergolong yang paling rendah di antara itemitem lain yang namun tetap fit.

Pada peneliti terdahulu, banyak penelitian hanya mencantumkan nilai koefisien alpha cornbach ( $\alpha$ ), misalnya AGO performance dan AGO mastery pada penelitian Urdan dan Midgley (2003) yaitu, $\alpha=0.86$, 0.85, 0.84 dan $\alpha=0.84,0.86,0.80$ pada ketiga kelompok kelas di sekolah dasar. Ganoda et. al. (2007), yaitu 0.85 dan 0.83. Menurut Midgley, et.al. (2000) koefisien alpha pada skala yang spesifik cenderung lebih tinggi dibandingkan dengan skala general.

Alpha cronbach digunakan untuk melihat keseluruhan skala. Apabila nilai alpha chronbach $>0.80$, maka skala tersebut reliabel. Reliabel artinya keabsahan alat ukur yang digunakan namun belum tentu valid itemitem skala tersebut. Metode validitas item yang sering digunakan adalah CFA. CFA menguji konstruk validitas yang didasarkan pada teori dan hipotesis. Ketika tes tersebut diujikan pada seseorang, relevan atau tidakkah mengukur trait yang diukur sesuai dengan area domainnya kisi-kisi dengan item.

Hasil analisis uji struktur internal AGO performance terdapat item-item yang saling berkorelasi. Hanya satu item yang tidak berkorelasi yaitu AGO5 "Penting bagi saya melakukan yang terbaik dibandingkan siswa lain di kelas". Indikator korelasi misalnya item AGO4, AGO8 - AGOI0 saling berkorelasi yang intinya "terlihat pintar". Pada hasil bifaktor AGO performance terdapat dua yaitu PI yaitu AGOI - AGO5 mengenai "melakukan yang terbaik" dan P2 yaitu AGO4, AGO8 - AGOIO mengenai "terlihat pintar". Terdapat satu item yang mengukur PI dan P2 yaitu AGO4 "Saya ingin menunjukkan kepada guru bahwa saya lebih pintar dari siswa lain di kelas". Item AGO4 berarti selain item tersebut mengukur tentang "melakukan yang terbaik" tetapi juga mengukur "terlihat pintar". Selanjutnya peneliti mengorelasikan PI dan P2, hasilnya signifikan yang artinya semakin individu melakukan yang terbaik semakin terlihat pintar atau sebaliknya. 
Di dalam analisis internal struktur AGO mastery, terdapat enam korelasi residual agar valid. Pada hasil tersebut, ada tiga item yang tidak berkorelasi yaitu AGOI7 "Penting bagi saya untuk belajar banyak materi baru tahun ini”, AGOI8 "Salah satu tujuan saya di kelas adalah belajar sebanyak mungkin yang saya bisa”, dan AGOI9 "Salah satu tujuan saya adalah menguasai banyak keterampilan baru tahun ini". AGOI7, AGOI8, AGOI9 dapat disimpulkan bahwa item-item tersebut mengukur satu konstruk yaitu AGO mastery.

Berdasarkan analisis model bifaktor AGO mastery, MI yaitu item AGOII-AGOI4 yang mengukur tentang "menyukai tugas" sedangkan M2 yaitu item AGOI7-AGO2I yang mengukur tentang "memahami tugas". Kedua faktor tersebut signifikan apabila dikorelasikan dan valid mengukur bifaktor AGO mastery. Di dalam analisis tersebut, terdapat dua item yaitu AGOI5 dan AGOI6 yang apabila di validitas pada MI atau M2 maka menghasilkan arah yang negatif atau tidak valid. AGOI5 "Alasan penting saya mengerjakan tugas kelas karena saya menikmatinya” dan AGOI6 “Saya mengerjakan tugas kelas karena saya tertarik dengan tugas tersebut" yang mengindikasikan bahwa individu dalam mengerjakan tugas karena keterpaksaan.

AGO performance berisi item-item yang menunjukan kepintaran (show up) individu terhadap teman, guru, dan orang lain, sedangkan AGO mastery berfokus pada penguasaan tugas. Uji struktur internal pada AGO mastery hanya alat ukur Midgley, et al (1998) atau AGO original yang semua itemnya valid dan ditambah satu item dari skala yang direvisi. Hasil tersebut karena prestasi individu berhubungan dengan minat dan kepercayaan atau keyakinan individu, sehingga ketika dianalisis struktur dimensinya menjadi terpecah (Midgley, Feldlaufer, \& Eccles, I989).

Di dalam analisis struktur internal, terdapat korelasi positif yang signifikan antara AGO performance dengan AGO mastery. Arah positif pada AGO performance dengan AGO mastery karena adaptasi individu, kognisi, dan regulasi diri terhadap prestasi (Wolters, 2004; Wolters, Yu, \& Pintrich, 1996). Selain itu, sebagai konsekuensi untuk mencapai sebuah prestasi maka individu harus menguasai (mastery) dan menunjukkan kepintarannya (performance) dalam belajar (Pintrich, Conley, \& Kempler, 2003)

Di dalam analisis MI, terdapat tiga item yang inkonsisten antara laki-laki dan perempuan yaitu AGO2 "Saya ingin melakukan yang terbaik dibandingkan siswa lain di kelas", AGOI7 "Penting bagi saya untuk belajar banyak materi baru tahun ini” dan AGO20 "Penting bagi saya bahwa saya benar-benar memahami tugas kelas”. AGOI7 dan AGO20 terdapat kesalahan dalam analisis menggunakan software M-Plus -"Error, Based on Group

Group I contains inconsistent categorical value". Kesalahan tersebut didasari oleh perbedaan kategori atau rating scale antar kelompok laki-laki dan perempuan yang berdampak pada perbedaan nilai threshold. Berdasarkan kesalahan tersebut, ternyata kelompok perempuan memiliki tiga kategori (tidak setuju, setuju, dan sangat setuju) sedangkan laki-laki memiliki empat kategori (sangat tidak setuju, tidak setuju, setuju, dan sangat setuju) sehingga peneliti membuang item-item tersebut. Pada analisis MI, model invariance harus saling mendukung antarmodel kelompok, misalnya kesamaan parameter yang diestimasi (Brown, 2006; Bowen \& Masa, 2015; Neil, Springer, \& Kamata, 2009).

Berdasarkan hasil validitas gender, laki-laki lebih tinggi tingkat signifikannya pada AGO performance dan perempuan berorientasi pada AGO mastery dibandingkan dengan perempuan. Hasil penelitian ini berkebalikan dengan Steinmayr dan Spinath (2008) bahwa perempuan lebih berorientasi AGO mastery dan AGO performance dibandingkan laki-laki. Hal ini sesuai dengan teori yang dilakukan oleh Theis dan Fischer (2017), yang dibuktikan oleh penelitiannya bahwa perempuan lebih tinggi tingkat AGO mastery dan laki-laki lebih tinggi AGO performance. Laki-laki lebih mengarah pada tugas-tugas yang praktis dan lingkungan belajar yang sesuai dengan pilihannya di sekolah (Dekker et.al, 20I3). Di dalam lingkungan belajar yang kompetitif, laki-laki

lebih berorientasi AGO performance dibandingkan perempuan dan hal tersebut juga didukung dengan orientasi AGO mastery (Midgley, Kaplan, \& Middleton, 200I). Perbedaan prestasi laki-laki dan perempuan 
berhubungan erat dengan potensi kognisinya. Oleh sebab itu, untuk menginvestigasi perbedaan tersebut harus disamakan atau dikontrol kemampuan kognisinya (Steinmayr \& Spinath, 2008).

Berdasarkan hasil analisis MI hanya model AGO performance sampai ke tahap metric invariance sedangkan AGO mastery tidak invariance. Pada penelitian Midgley et.al. (1998), dihasilkan hingga model metric invariance yang artinya teori dan data tidak sesuai dengan AGO mastery pada penelitian ini. Namun, untuk AGO performance terdapat perbedaan yang signifikan pada uji validitas dan model invariance pada kelompok gender. Lain halnya dengan penelitian Schwinger, Steinmayr, dan Spinath (2016) yang model secara signifikan sampai ke tahap strong invariance pada AGO performance dan AGO mastery. Signifikan hanya pada tahap scalar pada orientasi prestasi di universitas Hongkong (Ning, 2016) dan di SMP Amerika (Midgley et al, 1998). Ketika tahap metric invariance signifikan, hal tersebut berarti seluruh kelompok ada kesamaan konstruk laten (AGO) yang diteliti (Brown, 2006; Ren, Lugtig, \& Hox, 20I2).

Peneliti membagi instrumen AGO menjadi 4 kelompok yaitu $-\mathrm{P}-\mathrm{M},+\mathrm{P}-\mathrm{M},-\mathrm{P}+\mathrm{M}$, dan $+\mathrm{P}+\mathrm{M}$ yang didasari oleh Pintrich (2000a, 2000b). Pembagian kelompok dilakukan untuk mengklasifikasi penormaan individu agar para pengajar mudah dalam mengkategorikan AGO. kelompok -P -M memerlukan perhatian khusus dalam mengerjakan tugas dibandingkan kelompok $+\mathrm{P}+\mathrm{M}$ yang sudah mandiri dalam belajar. Di dalam norma kelompok $+\mathrm{P}-\mathrm{M}$ atau kelompok $\mathrm{AGO}$ performance, individu menunjukkan kemampuan dan kepintaran (show up) dibandingkan kelompok -P + M yang menguasai dan memahami tugas-tugas dalam belajar. AGO memiliki banyak tujuan (multiple goals) yang menghasilkan motivasi, afeksi, strategi yang digunakan, serta kinerja dalam belajar dan meraih prestasi individu (Pintrich, 2000a, 2000b; Pintrich, et al., 2003). Keterangan Penelitian ini menggunakan analisis kategori ordinal dengan estimasi default pada program Mplus. Pada analisis MI, peneliti menggunakan estimasi WLSMV.

\section{References}

Allen \& Yen. (1979). Introduction to Measurement Theory. California: Wadsworth, Inc.

Ames, C. (1992). Classrooms: Goals, structures, and student motivation. Journal of Educational Psychology, $84,26 \mathrm{I}-27 \mathrm{I}$.

Ames, C., \& Archer, J. (1988). Achievement goals in the classroom: students' learning strategies and motivation processes. Journal of Educational Psychology, 80(3), 260-267.

Anderman, E. M., Urdan, T., \& Roeser, R. (2003). The Patterns of Adaptive Learning Survey: History, Development, and Psychometric Properties. Trend Child, Washington D.C.

Archer, J. (1994). Achievement goals as a measure of motivation in university students. Contemporary Educational Psychology, 19, 430-446.

Bowen, N. K., \& Masa, R. D. (2015). Conducting measurement invariance tests with ordinal data: A guide for social work researchers. Journal of the Society for Social Work and Research, 6, (2), 2334- 23I.5 doi: I0.1086/68I607

Brislin, R. W. (1970). Back-translation for cross-cultural research. Journal of Cross-Cultural Psychology, I(3), I85-2I6. Doi: I0.I 177/I359I0457000I0030I

Brown, T. A. (2006). Confirmatory factor analysis for applied research. New York: Guilford Press.

Byrne, B. M. (2012). Structural equation modeling with Mplus: Basic concepts, applications and programming. New York: Routledge. 
Campbell, H., Barry, C., Joe, J., \& Finney, S. (2008). Configural, metric, and scalar invariance of the modified achievement goal questionnaire across African American and white university students. Educational and Psychological Measurement, 68(6), 988-I007. Doi: I0.I I77/00131644083I5269

Carr, S. (2006). An examination of multiple goals in children's physical education: Motivational effects of goal profiles and the role of perceived climate in multiple goal development. Journal of Sports Sciences, 24, 28I-297.

Chen, C. (2015). Incremental validity of achievement goals in predicting subjective well-being among university students. Journal of Cognitive Education and Psychology, I4, 38-62. Doi: I0.189I/I945-8959.I4.I.38

Cury, F., Elliot, A., Sarrazin, P., Fonseca, D. D., \& Rufo, M. (2002). The trichotomous achievement goal model and intrinsic motivation: a sequential mediational analysis. Joumal of Experimental Social Psychology, 38, 473-48I.

Dekker, S., Krabbendam, L., Lee, N. C., Boschloo, A., de Groot, R., \& Jolles, J. (2013). Sex differences in orientation in adolescents aged I0-19: The older boys adopt work avoidant goals twice as often as girls. Learning and Individual Differences, 26, 196-200. Doi: 10.1016/j.lindif.2012.07.0I I

Daniel, H. T. (20I4). Ujïan nasional, hanya Indonesia yang bisa begini... tragis!. Diunduh tanggal 2I April 2017 dari http://www.kompasiana.com/danielht/ujian-nasional-hanya-indonesia-yang-bisa-beginitragis_54f74ca8a333II7d2d8b4584

Darnon, C., Dompnier, B., \& Poortvliet, P. M. (2012). Achievement goals in educational contexts: A social psychology perspective. Social and Personality Psychology Compass, 6(10), 760-77I. Doi: I0.IIII/j.I75I-9004.20I2.00457.x

Duda, J., \& Nicholls, J. (1992). Dimensions of achievement motivation in schoolwork and sport. Journal of Educational Psychology, 84, 290.

Dweck, C. S. (1986). Motivational processes affecting learning. American Psychologist, 4I(I0), I040-I048. Doi: I0.1037/0003-066X.4I.I0.I040

Dweck, C, \& Leggett, E. (1988). A social-cognitive approach to motivation and personality. Psychological Review, 95, 256-273. Doi: I0.1037/0033-295X.95.2.256

Elliot, A. J. (1999). Approach and avoidance motivation and achievement goals. Educational Psychologist, 34, I49-I69. Doi: I0.I207/sI5326985ep3403_3

Elliott, E. S., \& Dweck, C. S. (1988). Goals: An approach to motivation and achievement. Journal of Personality and Social Psychology, 54, 5-I2. Doi:I0.I037/0022-35I4.54.I.5

Elliot, A. J., \& McGregor, H. A. (200I). A $2 \times 2$ achievement goal framework. Journal of Personality and Social Psychology, 80, 50I-5I9. Doi:I0.I037/0022-35I4.80.3.50I

Elliot, A. J., \& Murayama, K. (2008). On the measurement of achievement goals: Critique, illustration, and application. Journal of Educational Psychology, I00, 613-628. Doi: I0.1037/0022-0663.100.3.6I3

Elliot, A. J., Murayama, K., \& Pekrun, R. (20I I). A 3 x 2 achievement goal model. Journal of Educational Psychology, I03(3), 632-648. Doi: I0.1037/a0023952

Elliot, A. J., Thrash, T. M. (200I). Achievement goals and the hierarchical model of achievement motivation. Educational Psychology Review, I3 (2), I39 - I56. Doi: I040-726X/0I/0600-0I39

Fisher, S. L., \& Ford, J. K. (1988). Differential effects of learner effect and goal orientation in two learning outcomes. Personnel Psychology, 5I, 397-420. Doi: I0.I I I I/j.I744-6570.1998.tb0073I.x 
Gonida, E. N., Kiosseoglou, G., \& Voulala, K. (2007). Perceptions of parent goals and their contribution to student achievement goal orientation and engagement in the classroom: Grade-level differences across adolescence. European Journal of Psychology of Education, 22(I), 23-39.

Gonida, E. N., Voulala, K., \& Kiosseoglou, G. (2009). Students' achievement goal orientations and their behavioral and emotional engagement: Co-examining the role of perceived school goal structures and parent goals during adolescence. Learning and Individual Differences, I9, 53-60. Doi:I0.1016/j.lindif.2008.04.002

Hackel, T. S., Jones, M. H., Carbonneau, K. J., \& Mueller, C. E. (20I6). Re-examining achievement goal instrumentation: Convergent validity of AGQ and PALS. Contemporary Educational Psychology, 46, 73-80. Doi: I0.I0I6/j.cedpsych. 20I6.04.005

Hart. C. O., Mueller. C. E., Royal, K. D., \& Jones, M. H. (2013). Achievement goal validation among african american high school students: CFA and rasch results. Journal of Psychoeducational Assessment, 3I(3), 284- 299. Doi: I0.II77/ 07342829I2466726 Indriani. (2016). Penurunan nilai un smp di semua mata pelajaran. Dalam Ruslan Burhani (Ed). Diunduh tanggal 22 Mei 2017 dari http://www.antaranews.com/berita/56665I/ penurunan-nilai-un-smp-di-semua-mata-pelajaran

Jagachinski, C. M., \& Nicholls, J. G. (I984). Conceptions of ability and related affects in task involvement and ego involvement. Journal of Educational Psychology, (5), 909-9I9.

Kemendikbud. (2016). Indeks integritas ujian nasional (IIUN) SMA 2016 meningkat. Diunduh tanggal 2IApril 2017 dari https://www.kemdikbud.go.id/main/blog/ 20I6/05/ indeksintegritas-ujian-nasional-iiun-sma-2016-meningkat

Levy, I., Kaplan, A., \& Patrick, H. (2004). Early adolescents' achievement goals, social status, and attitudes towards cooperation with peers. Social Psychology of Education, 7, I27-I59.

Liu, W. C., Wang, C. K. J., Tan, O. S., Ee, J., \& Koh, C. (2009). Understanding students' motivation in project work: A $2 \times 2$ achievement goal approach. British Journal of Educational Psychology, 79, 87-I06.Doi:I0.1348/000709908X313767

Maehr, M., \& Midgley, C. (I99I). Enhancing student motivation: A school-wide approach. Educational Psychologist, 26, 399-427. Doi: I0.1080/00461520. I991.9653140

Middleton, M. J., Kaplan, A., \& Midgley, C. (2004). The change in middle school students' achievement goals in mathematics over time. Social Psychology of Education, 7, 289-3I I.

Midgley, C., Kaplan, A., Middleton, M. J., Maehr, M. L., Urdan, T., Anderman, L. H., et al. (1998). The development and validation of scales assessing students' achievement goal orientations. Contemporary Educational Psychology, 23, II3-I3I.

Midgley, C., Kaplan, A., \& Middleton, M. (200I). Performance-Approach Goals: Good For What, For Whom, Under What Circumstances, and At What Cost?. Journal of Educational Psychology, 93(I),77-86. Doi: I0.1037//0022-0663.93.1.77

Midgley, C., Maehr, M. L., Hruda, L. Z., Anderman, E., Anderman, L., Freeman, K. E., et al. (2000). Manual for the Patterns of Adaptive Learning Scales. University of Michigan.

Muis, K. R., Winne, P. H., \& Edward, O. V. (2009). Modern psychometrics for assessing achievement goal orientation: A Rasch analysis. British Journal of Educational Psychology, 79, 547-576. Doi:I0.1348/000709908X383472

Mullis, I. V. S., Martin, M. O., Foy, P., \& Hooper, M. (20I5). TIMSS 2015 international result in mathematics: Fourth grade mathematics. IEA: Lynch School of Education, Boston College. Diunduh 
tanggal I8 Mei 2017 dari http://timss2015.org/wp-content/uploads/filebase/full\%20pdfs/TI5International-Results-in-Mathematics-Grade-4.pdf

Murayama, K., Zhou. M., \& Nesbit, J. C. (2009). A cross-cultural examination of the psychometric properties of responses to the achievement goal questionnaire. Educational and Psychological Measurement, 69(2), 266-286. Doi: I0.II77/ 00I3I64408322017

Muthén, L.K. \& Muthén, B.O. (20I0). Mplus User's Guide (6th Ed). Los Angeles, CA: Muthén\&Muthén.

Neil, A., Springer, D. W., \& Kamata, A. (2009). Developing and validating rapid assessment instruments. New York: Oxford University Press.

Nicholls, J. G. (1984). Achievement motivation: Conceptions of ability, subjective experience, task choice, and performance. Psychological Review, 9I, 328-346.

Nicholls, J. G., Cheung, P. C, Lauer, J., \& Patashnick, M. (I989). Individual differences in academic motivation: Perceived ability, goals, beliefs, and values. Learning and Individual Differences, I, 63-84.

Pintrich, P. R. (2000). Multiple goals, multiple pathways: The role of goal orientation in learning and achievement. Journal of Educational Psychology, 92(3), 544-555. Doi: I0.1037//00220663.92.3.544

Pintrich, P. R. (2000). An achievement goal theory perspective on issues in motivation terminology, theory, and research. Contemporary Educational Psychology, 25, 92-104. Doi: I0.1006/ceps.1999.1017

Pintrich, P. R., Conley, A. M., \& Kempler, T. M. (2003). Current issues in achievement goal theory and research. International Journal of Educational Research, 39, 319-337. Doi: IO.IOI6/j.ijer.2004.06.002

Rinthapol, N., \& Duran, R. (201I). Validation of Goal Orientation Measure in PALS Among Latino Adolescents Participating in a College Outreach Program. US-China Education Review A 6, 825-830.

Ren, V. S., Lugtig, P., \& Hox, J. (2012). A checklist for testing measurement invariance. European Journal of Developmental Psychology, 9 (4). 486 - 492. http://joophox.net/publist/CecklistMeasInv.pdf Santrock, J. W. (20II). Educational psychology, 5ed. McGraw-Hill: New York, NY.

Salili, F., \& Lai, K. M. (2003). Learning and motivation of chinese students in hong kong: A longitudinal study of contextual influences on students'achievement orientation and performance. Psychology in the Schools, 40(I), 5I-70. Doi: 10.1002/pits.10069

Schwinger, M., Steinmayr, R., \& Spinath,B. (2016). Achievement goal profiles in elementary school: Antecedents, consequences, and longitudinal trajectories. Contemporary Educational Psychology, I-68. Doi: I0.1016/j.cedpsych.2016.05.006.

Shih, S. S. (2005). Taiwanese sixth graders' achievement goals and their motivation, strategy use, and grades: an examination of the multiple goal perspective. The Elementary School Journal, IO6(I), 39-58. Doi: I0.1086/496906

Shih, S. S. (2008). The relation of self- determination and achievement goals to Taiwanese eighth graders' behavioral and emotional engagement in schoolwork. The Elementary School Journal, IO8(4), 3I3334. Doi: $10.1086 / 528974$

Skaalvik, E. M. (1997). Self-enhancing and self-defeating ego orientation: Relations with task and avoidance orientation, achievement, self-perceptions, and anxiety. Journal of Educational Psychology, 89, 7I-8I. 
Steinmayr, R., \& Spinath, B. (2008). Sex differences in school achievement: What are the roles of personality and achievement motivation?. European Journal of Personality, 22, 185-209. Doi: 10.1002/per.676.

Theis, D., \& Fischer, N. (2017). Sex differences in the development of achievement goals in middle school. Learning and Individual Differences $x X x(x X X X) x x x-$ Doi: I0.1016/j.lindif.2017.05.006

Urdan, T., \& Midgley, C. (2003). Changes in the perceived classroom goal structure and pattern of adaptive learning during early adolescence. Contemporary Educational Psychology, 28, 524-55I. Doi:I0.I0I6/S036I-476X(02)00060-7.

VandenBos, G. R. (2015). APA dictionary of psychology, 2nd ed. Washington, DC: American Psychological Association.

Wolters, C. A. (2004). Advancing achievement goal theory: using goal structures and goal orientations to predict students' motivation, cognition, and achievement. Journal of Educational Psychology, 96(2), 236-250. Doi: 10.1037/0022-0663.96.2.236

Wolters, C. A., Yu, S. L., \& Pintrich, P. R. (1996) The relation between goal orientation and students' motivational beliefs and self-regulated learning. Learnign and Individual Differences, 8(3), 2 I I-238. 